\title{
MORREY TYPE TEICHMÜLLER SPACE AND HIGHER BERS MAPS
}

\author{
Guangming Hu, Yutong LiU, Yi Qi And Qingtian Shi
}

\begin{abstract}
In this paper, we focus on the set of univalent analytic functions $f$ with $\log f^{\prime} \in H_{K}^{2}$. Motivated by the study of BMO-Teichmüller spaces and Morrey type spaces, we establish serval equivalent characterizations of Morrey type domains. Furthermore, we show that the higher Bers maps, induced by the higher Schwarzian differential operators, are holomorphic in Morrey type Teichmüller spaces. Finally, one of connected components in the small pre-logarithmic derivative model of the Morrey type Teichmüller space is also obtained.
\end{abstract}

Mathematics subject classification (2010): 30C20, 30C62, 30D99.

Keywords and phrases: Schwarzian derivative, Teichmüller space, Morrey type space, Bers projection.

\section{REFERENCES}

[1] K. Astala And M. Zinsmeister, Teichmüller spaces and BMOA, Math. Ann., 289, (1991), 613625.

[2] J. Becker And C. Pommerenke, Uber die quasikonforme Fortsetzung schlicgter Funktionen, Math. Z., 161, (1978), 69-80.

[3] G. Buss, Higher Bers maps, Asian. J. Math., 16, (2012), 103-140.

[4] G. CUI, Integrably asymptotic affine homeomorphisms of the circle and Teichmüller spaces, Sci. China Ser. A., 43, (2000), 267-279.

[5] G. Cui And M. Zinsmeister, BMO Teichmüller spaces, Illinois J. Math., 48, (2004), 1223-1233.

[6] A. Douady AND C. EARLe, Conformally natural extension of homeomorphisms of the circle, Acta Math., 157, (1986), 23-48.

[7] M. Essén, H. Wulan And J. XiaO, Several function-theoretic characterizations of Möbius invariant $Q_{K}$ spaces, J. Funct. Anal., 230, (2006), 78-115.

[8] J. FAN AND J. HU, Holomorphic contraxtibility and other properties of the Weil-Petersson and VMO Teichmüller space, Ann. Acad. Sci. Fenn. Math., 41, (2016), 587-600.

[9] X. Feng, S. Huo And S. TANG, Universal Teichmüller spaces and $F(p, q, s)$ space, Ann. Acad. Sci. Fenn. Math., 42, (2017), 105-118.

[10] J. Hu AND O. MuZICIAn, Cross-ratio distortion and Douady-Earle extension: I. A new upper bound on quasiconformality, J. London Math. Soc., 86, 2(2012), 387-406.

[11] Y. Hu AND Y. SHEN, On quasisymmetric homeomorphisms, Israel J. Math., 191, (2012), 209-226.

[12] J. Jin AND S. TANG, On $Q_{K}$-Teichmüller spaces, J. Math. Anal. Appl., 467, 1(2018), 622-637.

[13] O. Letho, Univalent Functions and Teichmüller Spaces, Springer Berlin. 2012.

[14] P. Li, J. LiU AND Z. Lou, Integral operators on analytic Morrey spaces, Sci. China Math.,57, (2014), 1961-1974.

[15] J. LiU AND Z. Lou, Carleson measure for analytic Morrey spaces, Nonlinear Anal., 125, (2015), 423-432.

[16] S. NAG, The complex analytic theory of Teichmüller space, Wiley-Interscience, New York, 1988.

[17] C. POMmerenke, Boundary behaviour of conformal maps, Springer-Verlag, Berlin, 1992.

[18] E. SCHIPPERS, Distortion theorems for higher order Schwarzian derivatives of univalent functions, Proc. Amer. Math. Soc., 128, (2000), 3241-3249.

[19] Y. Shen AND H. WeI, Universal Teichmüller space and BMO, Adv. Math., 234, (2013), 129-148.

[20] S. TAng, G. Hu, Q. ShI AND J. Jin, Univalent functions and Dirichlet-Morrey space, Complex Var. Ellipitic, (2020), 1-11. DOI: 10.1080/17476933.2020.1769084. 
[21] S. TANG, G. Hu, Q. ShI And J. Jin, Higher Schwarzian derivative and Dirichlet Morrey space, Filomat., 33(17), (2019), 5489-5498.

[22] S. TANG AND J. Jin, Higher Bers maps and BMO-Teichmüller space, J. Math. Anal. Appl., 460(1), (2018), 63-73.

[23] J. WAng And J. XiaO, Analytic Campanato spaces by functionals and operators, J. Geom. Anal., 26, (2016), 2996-3018.

[24] Z. J. Wu AND CH. XIE, Q spaces and Morrey spaces, J. Funct. Anal., 201 , (2003), 282-297.

[25] H. Wulan and F. Ye, Universal Teichmüller space and $Q_{K}$ spaces, Ann. Acad. Sci. Fenn. Math., 39 , (2014), 691-709.

[26] H. Wulan and J. Zhou, $Q_{K}$ and Morrey type spaces, Ann. Acad. Sci. Fenn. Math. 38, 1(2013), 193-207.

[27] R. ZHAO, Distances from Bloch functions to some Möbius invariant spaces, Ann. Acad. Sci. Fenn. Math., 33, (2008), 303-313.

[28] K. ZHU, Bloch type spaces of analytic functions, Rocky Mountain J. Math., 23, 3(1993), 1143-1177.

[29] I. Zhuravlev, Model of the universal Teichmüller space, Siberian Math. J., 27 , (1986), 691-697. 